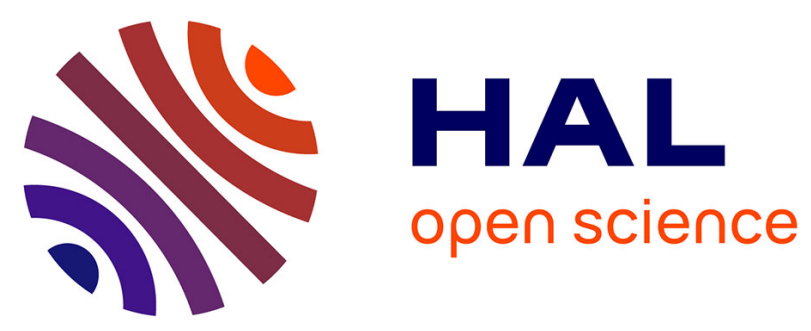

\title{
Elements of the West African monsoon circulation deduced from meteosat cloud winds and simultaneous aircraft measurements
}

\author{
Michel Desbois, Vincent Pircher, Bernard Pinty
}

\section{To cite this version:}

Michel Desbois, Vincent Pircher, Bernard Pinty. Elements of the West African monsoon circulation deduced from meteosat cloud winds and simultaneous aircraft measurements. Journal of Climate and Applied Meteorology, 1984. hal-01977179

HAL Id: hal-01977179

https://hal.uca.fr/hal-01977179

Submitted on 8 Jun 2021

HAL is a multi-disciplinary open access archive for the deposit and dissemination of scientific research documents, whether they are published or not. The documents may come from teaching and research institutions in France or abroad, or from public or private research centers.
L'archive ouverte pluridisciplinaire HAL, est destinée au dépôt et à la diffusion de documents scientifiques de niveau recherche, publiés ou non, émanant des établissements d'enseignement et de recherche français ou étrangers, des laboratoires publics ou privés. 


\title{
Elements of the West African Monsoon Circulation Deduced from METEOSAT Cloud Winds and Simultaneous Aircraft Measurements
}

\author{
MICHEL DESBOIS \\ LMD/CNRS, 91128 Palaiseau Cedex, France \\ VINCENT PIRCHER \\ EERM/DMN, Magny-les-Hameaux, France \\ BERNARD PINTY \\ LAMP/CNRS, Clermont-Ferrand, France
}

10 March 1983 and 16 July 1983

\begin{abstract}
Cloud winds derived from the European geostationary satellite METEOSAT for the region of the west African monsoon are validated by DC-7 aircraft measurements for the low levels of the tropical atmosphere. Since the two sets of results are in agreement, it appears that lowest level cumuli as well as stratocumuli can be used as tracers of the actual wind field. The satellite wind fields show a large-scale circulation characterized by two opposite flows in the lower layers: the southwesterly monsoon flow near the sea surface and a northeasterly flow above, at approximately the $2000 \mathrm{~m}$ level.
\end{abstract}

\section{Introduction}

Satellite imagery is now currently used to produce cloud motion wind fields for operational purposes as well as for research studies (Hubert and Whitney, 1971; Leese et al., 1971; Sadler and Lim, 1981). Whatever the method, optical, automatic or interactive, one major problem is the determination of the precise height at which the cloud wind has to be assigned. For largescale analyses, the wind fields are generally attributed to only three levels: high, medium and low. For more detailed studies, especially when the satellite measurements detect very different flows for very close layers, in situ measurements appear necessary to validate the cloud winds. This was made possible during WAMEX (West African Monsoon Experiment), as the METEOSAT satellite imagery was available together with an instrumented DC-7 aircraft investigation. The purpose of this paper is to present results of the comparison between satellite-derived cloud winds and the aircraft winds and to infer some conclusions about the large-scale African monsoon circulation.

\section{Extraction of the satellite cloud winds}

Cloud wind extraction is made in Laboratoire de Météorologie Dynamique (LMD) by means of an optical technique already used in many other studies, especially for intercomparison measurements and Indian monsoon studies; this technique is described, for example, in Cadet and Desbois (1980) and Desbois (1981). In the present case, the cloud motion is determined from two successive METEOSAT pictures in the visible channel $(5 \mathrm{~km}$ resolution in the regular operational mode of the satellite), whereas the level of the clouds is estimated roughly from one single IR picture. More detailed evaluations of the cloud top temperature are carried out on an interactive TV-computer system.

Three factors can contribute significantly to a bad wind estimation: 1) an error in the tracking of the cloud, 2) a wrong height given to a cloud and 3) a wrong wind vector due to cloud displacements by nonadvective effects. The first kind of error is minimal with an optical correlator, but can be significant for clouds with ill-defined contours. The second one is more difficult to exclude as we are working on small clouds (partial pixel coverage), including some semitransparent ones (emissivity less than 1), in low levels of a very humid tropical atmosphere (large atmospheric corrections due to water vapor absorption). The third factor is minimized in our study, as clouds have a life time greater than half an hour and as the analysis is carried out mainly over the sea where local thermal effects are less than over the continent; however, one cannot a priori exclude a cloud propagation due to a wave motion.

In the present study, due to difficulties in the access of archived data, the wind field extraction was limited 
to 4 days at the beginning of August 1979 (7-10 August). The image pairs used were from 1200 and 1230 GMT, except for the eight when wind fields were computed between 1000 and 1030, 1200 and 1230, 1300 and 1330,1400 and 1430 and between 1500 and 1530 to describe the evolution of the circulation during the day.

The wind fields extracted for the four days and the different hours show very similar characteristics at large scale. Therefore, we will first restrict this study to the case of 8 August, when in situ measurements by an instrumented aircraft were also available.

\section{Case of 8 August 1979}

\section{a. Cloud observations}

On 8 August 1979 , the DC-7 aircraft flew from $9^{\circ} \mathrm{W}$ to $3^{\circ} \mathrm{E}$ above the Gulf of Guinea at altitudes ranging from approximately 0.5 to $3.0 \mathrm{~km}$. The results concerning the observed dynamical and thermodynamical features of the investigated layer are given by Pinty and Soulage (1983). Besides these results, the cloud description is available along the flight track from visual observations made by the experimentators aboard the aircraft. These observations are shown schematically in Fig. 1a from $9^{\circ} \mathrm{W}$ to $3^{\circ} \mathrm{E}$. The zone of transition between dry and monsoonal air and the region where the northerlies occur are also shown in this figure. The observed clouds are mainly small cumuli with a small vertical extent through the monsoon layer and alto or stratocumuli found near the zone of transition topping the monsoon layer. However, east of $5^{\circ} \mathrm{E}$, it appears that the cumuli are more developed and reach the 2 $\mathrm{km}$ level. It is apparent that the highest level clouds lie in a northerly flow.

The METEOSAT 1500 GMT "visible" picture (Fig. 2a) shows a typical cloud pattern over the study area.
The small cumuli are often organized in "cloud streets" along the monsoon flux over the ocean and become denser over the continent. The alto or stratocumuli appear as bands of diffuse clouds parallel to the coastline. We will call them stratocumuli hereafter. The characteristic lifetime of these clouds is of the order of one hour for the smallest traceable cumuli over the sea (10 km scale) and several hours for the stratocumuli (20 to more than $100 \mathrm{~km}$ scales). As all these clouds are at relatively low levels (even over the continent) and as there is a large atmospheric absorption at this level even in the window channel, they do not: show a clear contrast with the background and appear in grey on the METEOSAT IR picture (Fig. 2b). Histograms of the radiances allow determination of approximate average values of the apparent radiative temperature of the different elements of the scene (including the atmospheric effects): $293 \mathrm{~K}$ for the sea, $289 \mathrm{~K}$ for the small cumuli and $283-287 \mathrm{~K}$ for the altocumuli. It is not possible to infer from these values real sea or cloud top temperatures, as the large atmospheric correction cannot be accurately determined and as the values measured also include the effects of partial cloud cover of the pixels (particularly for the small cumuli) and sometimes of semitransparency of the clouds (particularly for the stratocumuli). The values given here are just an indication of the small difference of levels between the different clouds. This kind of indication is also shown in Fig. 1b, where we have plotted the value of the IR radiance measured by the satellite along the plane track. It appears that the variation of this radiance is in agreement with the cloud observations made from the aircraft (Fig. 1a). Therefore, taking the DC-7 observations into account, it will be assumed in the following satellite wind analysis that the small cumuli correspond roughly to the $0.5 \mathrm{~km}$ level, whereas the stratocumuli correspond to the $2.0 \mathrm{~km}$ level.

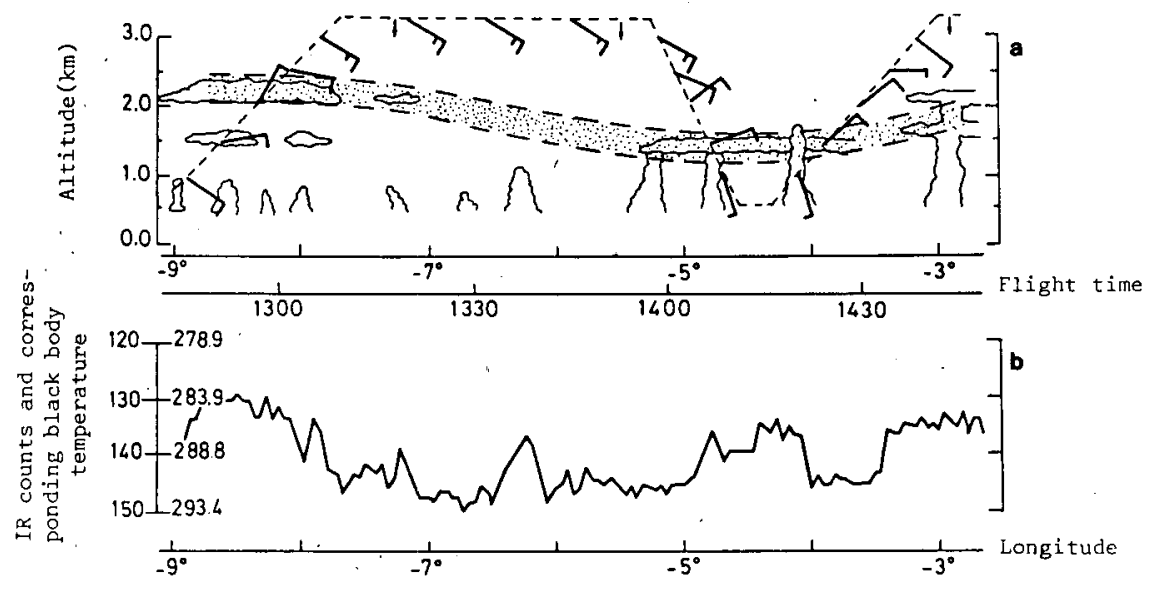

FiG. 1. (a) Cloud pattern derived from observations aboard the DC-7 aircraft (from $9^{\circ} \mathrm{W}$ to $3^{\circ} \mathrm{E}$ ). (b) METEOSAT IR counts and corresponding blackbody temperature measured along the flight track at 1400 GMT. 


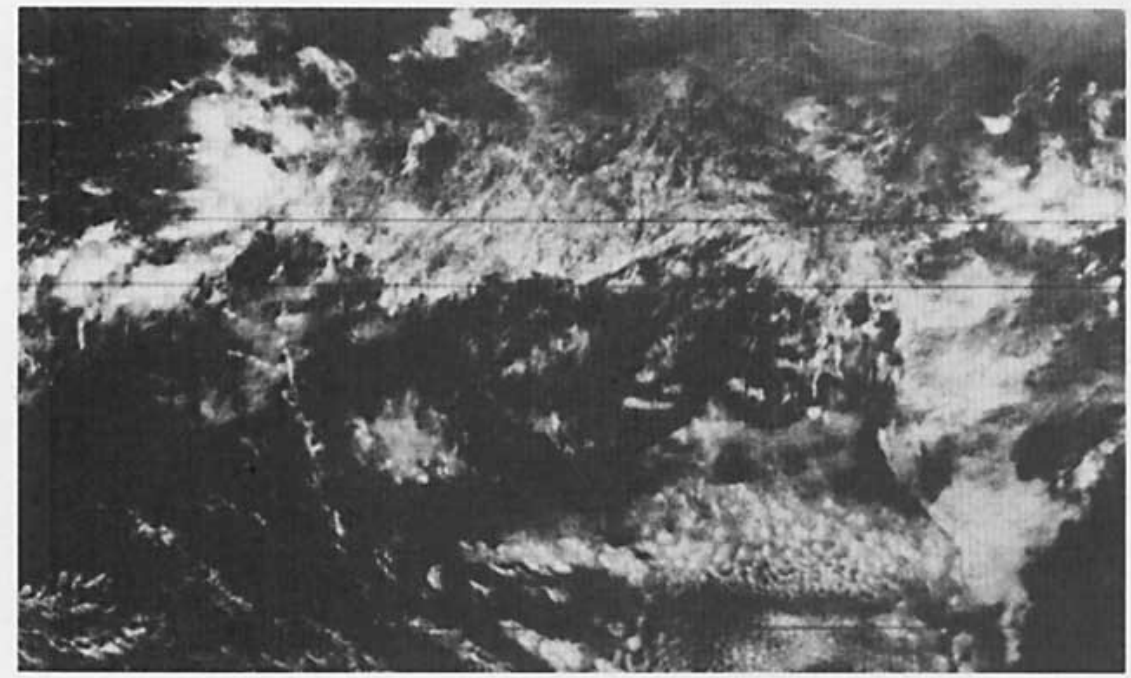

a

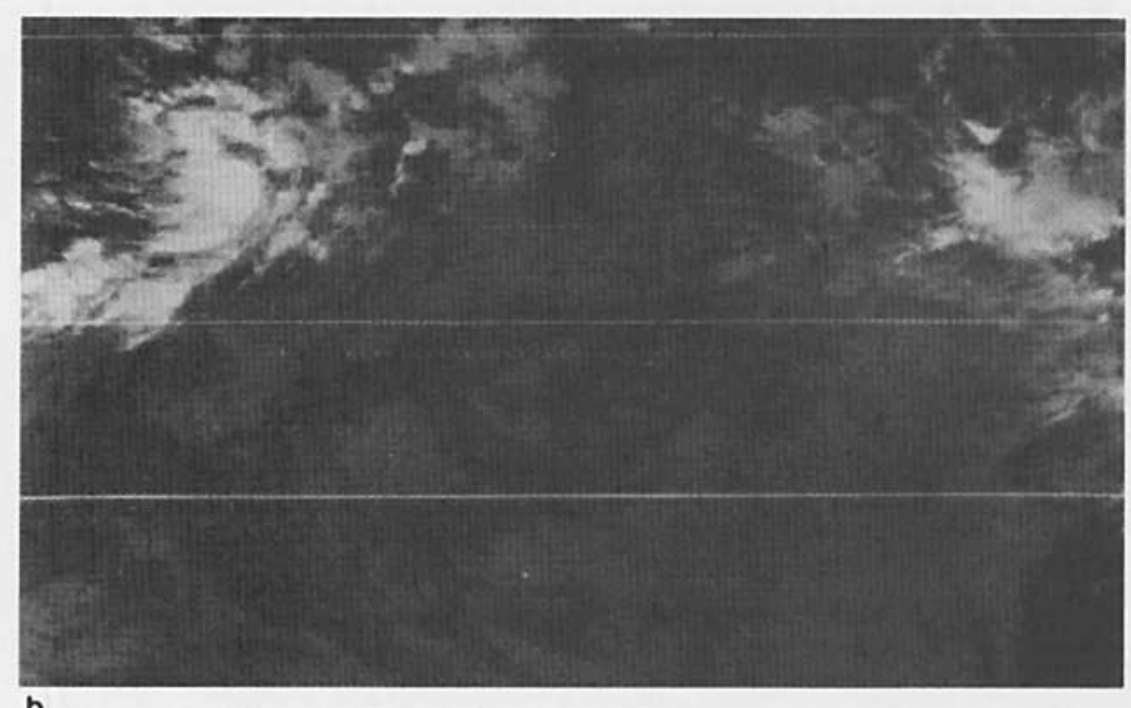

FIG. 2. (a) METEOSAT VIS picture and (b) METEOSAT IR picture at 1500 GMT 8 August 1979.

\section{b. Satellite wind field analysis and validation}

METEOSAT film loops have been constructed from the sequence of 8 August; northward motion of the small cumuli and southward motion of the stratocumuli is evident on these loops. This greatly helps discrimination of the two layers in the wind field analysis. The results obtained on 8 August 1979 at 1500 are given in Fig. 3 for the two levels. At the lowest level, the south-southwesterly flow is described by many wind vectors, as the small cumuli are numerous and can be easily followed. In the case of the northerly flow, fewer cloud tracers have been selected and there are some erratic measurements. This is mainly due to the use of clouds which are more diffuse and exhibit less precise contours.
In order to compare satellite and in situ wind measurements, the satellite winds have been interpolated on the flight track with a Cressman method. For the $0.5 \mathrm{~km}$ level (Fig. $4 \mathrm{a}$ ), the agreement between the two estimations is quite satisfactory all along the flight track. With regard to the $2.0 \mathrm{~km}$ level (Fig. $4 \mathrm{~b}$ ), the agreement is still very good in the western part of the track, but there is an increasing discrepancy at the eastern end of the track, especially for the wind direction. This can be attributed to a poor definition of the cloud tracers over this region, as the stratocumuli are particularly ill-defined and somewhat semitransparent. Because the motion of the lower clouds can be seen through the stratocumuli, it is very difficult to obtain good precision on these cloud motions. However, the vector difference between the compared winds never exceeds $5 \mathrm{~m} \mathrm{~s}^{-1}$, 

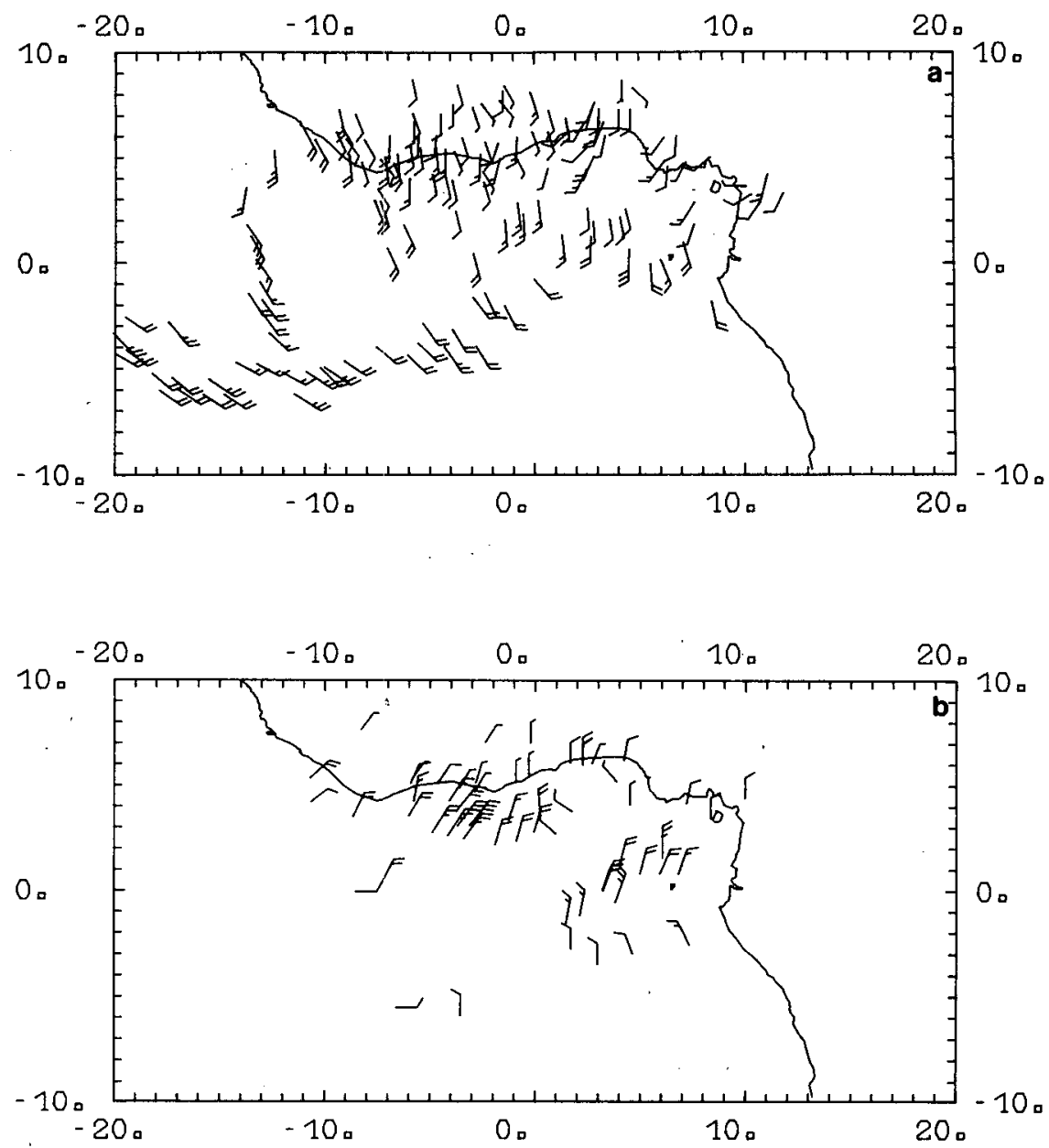

FIG. 3. METEOSAT-derived cloud winds at (a) the lowest level $(0.5 \mathrm{~km}$ height). and (b) the upper level $(2.0 \mathrm{~km}$ height).

which is within the precision of the optical correlator method. Other comparisons have been done with pilot wind soundings along the coast of Africa. The two opposite direction flows can also be seen, but the comparison is not as good, due to local coastal effects.

\section{c. Comparison with other cloud wind analyses}

During the summer of 1979 , two other institutions produced cloud winds with METEOSAT over the same region: the European Space Operating Center (ESOC) in Darmstadt (ESA, 1980) and the Space Science and Engineering Center of the University of Wisconsin in Madison (Balogun, 1982). The ESOC produced cloud winds for only 8 August at 1200 GMT. The so-called "low-level wind field" clearly shows the occurrence of a northerly wind over the Gulf of Guinea. As this analysis is made from IR pictures alone, the present study suggests that the ESOC wind vectors are principally derived from the highest existing clouds, namely the stratocumuli topping the monsoon layer. The small cumuli of the monsoon layer can be discerned only on the visible pictures, and that example emphasizes the necessity of using them for proper determination of the low-level cloud winds, especially in tropical regions. However, the ESOC analysis confirms the results obtained here for the stratocumuli motion.

\section{d. Extent and persistence of the flow pattern observed}

The observed wind pattern with two opposite flows at levels 0.5 and $2.0 \mathrm{~km}$, which has been discovered by the airplane measurement, is shown by the satellite measurement to be a large-scale phenomenon over the continent as well as over the gulf of Guinea (from $7^{\circ} \mathrm{N}$ to $3^{\circ} \mathrm{S}$ and from $10^{\circ} \mathrm{W}$ to $10^{\circ} \mathrm{E}$, at least). The case of 8 August 1979 is not an isolated one. For the other three days of the LMD analysis, the southerly and northerly flows are still present together. Moreover, the satellite cloud wind analysis carried out at the University of Wisconsin shows similar patterns in many cases from 15 July to 15 August 1979. The ESOC 
(a)
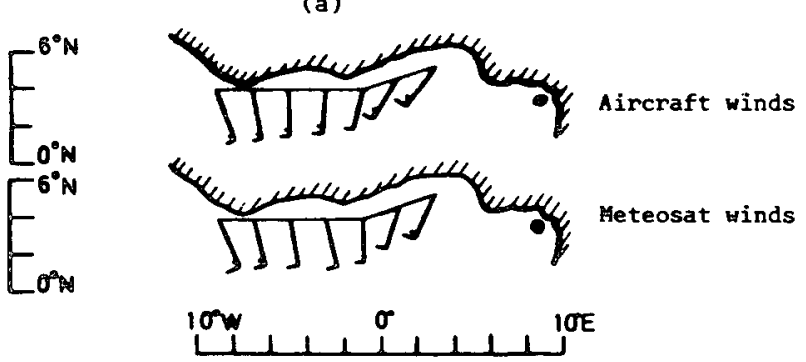

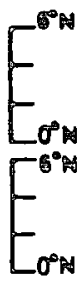

(b)
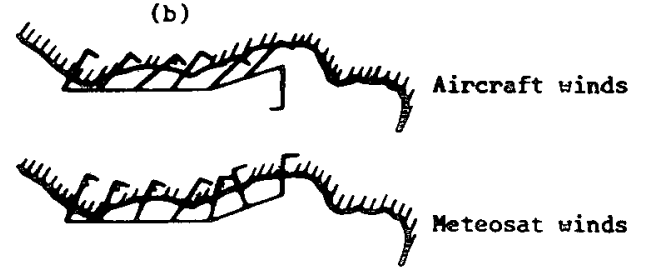

$L^{10 \%}+1,0^{\circ}, 1,1,10^{\circ} \mathrm{E}$

FIG. 4. (a) Comparison between satellite and aircraft winds along the flight track at $0.5 \mathrm{~km}$ level. (b) As in (a) but at $2.0 \mathrm{~km}$ level.

analyses do not show the southerly low-level flow, for the reason we pointed out before, but most of the time they do show the northerly flow during all of the summer season.

\section{Conclusion}

The present study shows how precise knowledge of cloud heights from in situ observations can be used in order to determine the altitude at which satellite wind estimations are carried out. This becomes particularly important at low levels over tropical regions where the large amount of water vapor contained in the atmosphere contributes significantly to the radiance received by the satellite.

In the case studied here, the comparison for two low levels between METEOSAT-derived cloud winds and winds measurements from aircraft appears quite satisfactory. This result indicates that the small cumuli and the stratocumuli constitute good tracers for the low-level wind fields. It is shown that the low-level southerly monsoonal flow (which is not apparent from ESOC's analysis) is topped by a large-scale northerly flow. Since this thin northerly flow is materialized by stratocumuli, its direction and strength can be estimated from satellite data at a level corresponding to the top of the monsoon layer.

It has been shown by Pinty and Soulage (1983) from the study of the rawinsonde data along the African coast, that the observed northerly wind was consistent with easterly waves occurring in the region of the plane flight. However, the large-scale extension of this flow, even south of the equator, as well as its frequency of occurrence, makes it necessary to confirm this hypothesis with further measurements, especially regarding the extension of easterly waves over the ocean.

\section{REFERENCES}

Balogun, E. E., 1982: West African monsoon windsets from geostationary satellite pictures. SSEC Report. University of Wisconsin, Madison, $96 \mathrm{pp}$.

Cadet, C., and M. Desbois, 1980: The burst of the 1978 Indian summer monsoon as seen from METEOSAT. Mon. Wea. Rev., 108, 1967-1701.

Desbois, M., 1981: Representativeness of cloud motion winds deduced from GOES I.O. satellite imagery for the description of the Indian summer monsoon. Proc. Int. Conf. on Early Results of FGGE and Large Scale Aspects of its Monsoon Experiment, Tallahassee, ICSU/WMO/GARP, 5 pp.

ESA, 1980: METEOSAT Cloud Winds, June-July-August-September 1979. Edited by European Space Operation Center, Darmstadt, Germany, $400 \mathrm{pp}$.

Hubert, L. F., and L. F. Whitney, 1971: Wind estimation from geostationary satellite pictures. Mon. Wea. Rev., 99, 665-672.

Leese, J. A., C. S. Novak and B. B. Clark, 1971: An automated technique for obtaining cloud motions from geosynchronous data using cross correlation. J. Appl. Meteor., 10, 118-132.

Pinty, B., and R. G. Soulage, 1983: Observation of a variable northerly wind component in the African monsoon layer. Mon. Wea. Rev., $111,1886-1890$.

Sadler, J. C., and J. T. Lim, 1981: Monitoring the monsoon outflow from geosynchronous satellite data. Monsoon Dynamics, J. Lighthill and R. P. Pearce, Eds., Cambridge University Press, $735 \mathrm{pp}$. 